\title{
On representation of the internal spherical functions and their derivatives in the planetary coordinate system
}

\author{
Fys M. M., Brydun A. M., Yurkiv M. I. \\ Lviv Polytechnic National University, \\ 12 S. Bandera Str., 79013, Lviv, Ukraine
}

(Received 25 March 2019; Accepted 23 September 2019)

\begin{abstract}
The expressions of spherical functions and their derivatives in a Cartesian coordinate system are obtained. In opposite to the representation of polynomials in a spherical coordinate system, the derived recurrence relations make it possible to use them in the description of physical processes, and the obtained formulae for derivatives of spherical functions within the sphere allow obtaining the solutions to the problems of mathematical physics for spherical bodies in a Cartesian coordinate system. This approach has its advantages precisely in the applied problems. For example, for the determination of the artificial satellites orbits, it is necessary to represent the external potential of gravitation and its derivatives for the GPS systems in a Cartesian coordinate system. Investigation of the internal structure of Earth and astrometric studies of processes in galaxies are associated with the study of internal potential, and, consequently, there is a necessity for its presentation in the Cartesian coordinates.
\end{abstract}

Keywords: planet mass distribution, Cauchy formula, Legendre polynomials, threedimensional density model, expansion coefficients.

2000 MSC: 86A20, 86A30, 86A99

UDC: $528.33: 551.24$

DOI: $10.23939 / \mathrm{mmc} 2019.02 .251$

\section{Introduction}

When solving problems of mathematical physics for spherical bodies, spherical functions and their derivatives are used mainly in a spherical coordinate system. However, in applications, it often becomes necessary to represent them in a Cartesian coordinate system $[1,2]$. Without emphasizing this problem in general, let us dwell on a concrete example. The GPS(GNSS) technology provides spatial placement of the object in a rectangular coordinate system using artificial satellites (AS). Forecasting of AS and planets orbits is impossible without taking into account their gravitational fields. The trajectories of the AS are determined by differential equations, which coefficients containing components of the potential and its derivatives in a Cartesian coordinate system. Investigation of the structure of the potential expansion coefficients in a series by spherical polynomials also implies their representation in a Cartesian coordinate system $[1,3-5]$.

\section{Statement of the problem}

A planet potential $\tau$ is determined according to the known formula [6]

$$
V(P)=G \int_{\tau} \frac{\delta(Q)}{r(Q, P)} d \tau_{Q}
$$

where $G$ is a gravitational constant; $r(Q, P)=\sqrt{\rho^{2}-2 \rho R \cos \varphi+R^{2}}$ is a distance between the points $P(x, y, z)$ and $Q(\xi, \eta, \zeta) ; \rho, R$ are the radii-vectors of the points $P, Q$ and $\varphi$ is the angle between them, respectively. 
Using (1) and series expansions of $r(Q, P)$, we obtain known representation of the potential by an infinite sum

$$
V=\frac{G M}{a_{e}}\left(1+\sum_{n=1}^{\infty} \frac{1}{R^{n}}\left(\sum_{k=0}^{n} P_{n}^{k}(\cos \theta)\left(C_{n k} \cos k \lambda+S_{n k} \sin k \lambda\right)\right)\right),
$$

where $M$ is a planet's mass, $a_{e}$ is equatorial radius, $P_{n}^{k}(\cos \theta)$ is associated Legendre polynomials and $C_{n k}, S_{n k}$ are series expansion coefficients which are defined by the following formulae

$$
C_{n k}=\frac{R R \cdot G M}{a_{e}^{n}} \int_{\tau} \rho^{n} P_{n}^{k}\left(\cos \theta^{\prime}\right) \cos k \lambda^{\prime} d \tau_{Q}, \quad S_{n k}=\frac{R R \cdot G M}{a_{e}^{n}} \int_{\tau} \rho^{n} P_{n}^{k}\left(\cos \theta^{\prime}\right) \sin k \lambda^{\prime} d \tau_{Q},
$$

where $R R= \begin{cases}1, & k=0 \\ 2, & k \neq 0\end{cases}$

Using complex variables, the equalities (3) can be written in the following form

$$
\begin{aligned}
C_{n k}+i S_{n k} & =\frac{R R \cdot G M}{a_{e}^{n}}\left(\int_{\tau} \rho^{n} P_{n}^{k}\left(\cos \theta^{\prime}\right)\left(\cos k \lambda^{\prime}+i \sin k \lambda^{\prime}\right) d \tau_{Q}\right) \\
& =\frac{R R \cdot G M}{a_{e}^{n}}\left(\int_{\tau} \rho^{n} P_{n}^{k}\left(\cos \theta^{\prime}\right)\left(\cos \lambda^{\prime}+i \sin \lambda^{\prime}\right)^{k} d \tau_{Q}\right) .
\end{aligned}
$$

Here and further $(R, \theta, \lambda),\left(\rho, \theta^{\prime}, \lambda^{\prime}\right)$ are spherical coordinates of the points $P$ and $Q$, respectively.

A set of functions

$$
\frac{P_{n}^{k}(\cos \theta) \cos k \lambda}{R^{n}}, \quad \frac{P_{n}^{k}(\cos \theta) \sin k \lambda}{R^{n}}
$$

is defined as external spherical functions and, respectively, $\rho^{n} P_{n}^{k}\left(\cos \theta^{\prime}\right) \cos k \lambda^{\prime}, \rho^{n} P_{n}^{k}\left(\cos \theta^{\prime}\right) \sin k \lambda^{\prime}$ are internal spherical functions.

Further, using a generalized representation, we obtain

$$
\begin{aligned}
V_{n, k} & =\frac{P_{n}^{k}(\cos \theta) \cos k \lambda}{R^{n}}+i \frac{P_{n}^{k}(\cos \theta) \sin k \lambda}{R^{n}}=V_{n, k}^{1}+i V_{n, k}^{2}, \\
U_{n, k} & =\frac{(n-k) !}{(n+k) !} \rho^{n} P_{n}^{k}\left(\cos \theta^{\prime}\right) \cos k \lambda^{\prime}+i \rho^{n} P_{n}^{k}\left(\cos \theta^{\prime}\right) \sin k \lambda^{\prime}=U_{n, k}^{1}+i U_{n, k}^{2} .
\end{aligned}
$$

It is known that series (2) converges outside the sphere $S$, and inside convergence takes place under certain restrictions (Bjerhammar convergence sphere is determined [6]).

Usage of the representation (2) enables the practical application of external potential in the study of Earth and other celestial bodies. The definition of an artificial satellite motion involves numerical integration of differential equations in the Cartesian coordinate system, which coefficients contain the components of the external gravitational field and its derivatives in the Cartesian coordinate system. For external spherical functions, this problem is solved in $[3,7]$ and adapted for program realization in [1].

Internal spherical functions in geodesy are not used practically but their application is wider in geophysics, which can be explained mainly by the possibility of using Stokes constants in the construction of three-dimensional models of the interior mass distribution of the planets and involves their representation in the Cartesian coordinate system.

In the papers $[5,8]$, the relation between the Stokes constants and power density moments that are essentially expressions of the internal spherical functions in a rectangular coordinate system were obtained. However, the functions (coefficients in sums) are presented in different papers in various forms with an accuracy to a multiplier. Hereinafter, we will follow the notation and the way of conclusions as in [7]. 


\section{Derivation of the formulae}

First of all, we should consider the relationships between Cartesian and spherical coordinate systems

$$
\xi=\rho \sin \theta^{\prime} \cos \lambda^{\prime}, \quad \eta=\sin \theta^{\prime} \sin \lambda^{\prime}, \quad \zeta=\rho \cos \theta^{\prime} .
$$

or, conversely,

$$
\rho=\sqrt{\xi^{2}+\eta^{2}+\zeta^{2}}, \quad \cos \theta^{\prime}=\frac{\zeta}{\rho}, \quad \sigma=\sqrt{\xi^{2}+\eta^{2}}, \quad \cos \lambda^{\prime}=\frac{\xi}{\sigma}, \quad \sin \lambda^{\prime}=\frac{\eta}{\sigma} .
$$

Harmonics polynomials within a sphere are defined as follows

$$
H_{n, k}=(\xi+i \eta)^{k} Z_{n, k},
$$

where

$$
Z_{n, k}=\frac{(n+k) !}{2^{k}} \sum_{m=0}^{\left[\frac{n-k}{2}\right]} \frac{(-1)^{m} \zeta^{n-k-2 m} \sigma^{2 m}}{2^{2 m} m !(m+k) !(n-k-2 m) !} .
$$

In context of binding to the Stokes constants, polynomials $U_{n, k}$ are determined

$$
U_{n, k}=\frac{(n-k) !}{(n+k) !} H_{n, k}
$$

Hence,

$$
U_{n, k}=\frac{(n-k) !}{2^{k}} \sum_{m=0}^{\left[\frac{n-k}{2}\right]} \frac{(-1)^{m} \zeta^{n-k-2 m} \sigma^{2 m}}{2^{2 m} m !(m+k) !(n-k-2 m) !}(\xi+i \eta)^{k} .
$$

Formula (4) is a variant of representation of internal spherical functions in the Cartesian coordinate system.

Let us proceed to the definition of derivatives

$$
\frac{\partial^{t}\left(U_{n, k}\right)}{\partial \xi^{\alpha} \partial \eta^{\beta} \partial \zeta^{\gamma}}, \quad(t=\alpha+\beta+\gamma, \quad \nu=\alpha+\beta)
$$

Firstly, we should define the derivatives by $\xi$. From formula (4) it follows that values (5) are zero for $\gamma>n-k$. Differentiating this relationship $\gamma$ times yields

$$
\frac{\partial^{\gamma}\left(U_{n, k}\right)}{\partial \zeta^{\gamma}}=\frac{(n-k) !}{2^{k}} \sum_{m=0}^{\left[\frac{n-k}{2}\right]} \frac{(-1)^{m} \zeta^{n-k-2 m-\gamma} \sigma^{2^{m}}(n-k-2 m) !}{2^{2 m} m !(m+k) !(n-k-2 m-\gamma) !}(\xi+i \eta)^{k} .
$$

Correspondingly,

$$
\frac{\partial^{\gamma}\left(U_{n, k}\right)}{\partial \zeta^{\gamma}}=\left\{\begin{array}{cc}
\frac{(n-k) !}{(n-k-\gamma) !} U_{n-\gamma, k}, & \gamma \leqslant n-k \\
0, & \gamma>n-k .
\end{array}\right.
$$

Derivation of expressions for derivatives by variables $\xi, \eta$ is more complicated. First of all, we introduce two operators

Hence,

$$
\mathrm{P}=\frac{\partial}{\partial \xi}+i \frac{\partial}{\partial \eta}, \quad \mathrm{M}=\frac{\partial}{\partial \xi}-i \frac{\partial}{\partial \eta}
$$

$$
\frac{\partial}{\partial \xi}=\frac{1}{2}(\mathrm{P}+\mathrm{M}), \quad \frac{\partial}{\partial \eta}=\frac{-i}{2}(\mathrm{P}-\mathrm{M})
$$

Mathematical Modeling and Computing, Vol. 6, No. 2, pp. 251-257 (2019) 
therefore,

$$
\begin{aligned}
\frac{\partial^{\nu}}{\partial \xi^{\alpha} \partial \eta^{\beta}} & =\frac{(-i)^{\beta}}{2^{\nu}}(\mathrm{P}+\mathrm{M})^{\alpha}(\mathrm{P}-\mathrm{M})^{\beta}=\frac{(-i)^{\beta}}{2^{\nu}} \sum_{s=0}^{\alpha} \frac{\alpha !}{s !(\alpha-s) !} \mathrm{P}^{\alpha-s} \mathrm{M}^{s} \sum_{j=0}^{\beta} \frac{\beta !(-1)^{j}}{j !(\beta-j) !} \mathrm{P}^{\beta-j} \mathrm{M}^{j} \\
& =\frac{(-i)^{\beta} \alpha ! \beta !}{2^{\nu}} \sum_{l=0}^{\nu} \sum_{s+j=l} \frac{(-1)^{j}}{s !(\alpha-s) ! j !(\beta-j) !} \mathrm{P}^{\nu-l} \mathrm{M}^{l} .
\end{aligned}
$$

The previous formula will be represented in a more convenient form for further transformations

$$
\frac{\partial^{\nu}}{\partial \xi^{\alpha} \partial \eta^{\beta}}=\frac{(-i)^{\beta} \alpha ! \beta !}{2^{\alpha+\beta}} \sum_{l=0}^{\left[\frac{\nu}{2}\right]-\lambda}(\mathrm{PM})^{l}\left(D_{\alpha, \beta}^{l} \mathrm{P}^{\nu-2 l}+D_{\alpha, \beta}^{\nu-l} \mathrm{M}^{\nu-2 l}\right)+\lambda D_{\alpha, \beta}^{\left[\frac{\nu}{2}\right]}(\mathrm{PM})^{\left[\frac{\nu}{2}\right]}
$$

where $D_{\alpha, \beta}^{l}=\sum_{s+j=l} \frac{(-1)^{j}}{s !(\alpha-s) ! j !(\beta-j) !}$ and $\lambda= \begin{cases}1, & \nu \text { is even; } \\ 0, & \nu \text { is odd. }\end{cases}$

We should define the result of operators PM, P, M. Thus,

$$
\mathrm{PM}=\left(\frac{\partial}{\partial \xi}+i \frac{\partial}{\partial \eta}\right)\left(\frac{\partial}{\partial \xi}-i \frac{\partial}{\partial \eta}\right)=\frac{\partial^{2}}{\partial \xi^{2}}+\frac{\partial^{2}}{\partial \eta^{2}}=-\frac{\partial^{2}}{\partial \zeta^{2}}
$$

Taking into account (6) for harmonic function $U_{n, k}$, from the Laplace equation, we obtain

$$
\operatorname{PM}\left(U_{n, k}\right)=-\frac{(n-k) !}{(n-k-2) !} U_{n-2, k}
$$

Therefore, reusing this operator leads to

$$
(\mathrm{PM})^{l}\left(U_{n, k}\right)=(-1)^{l} \frac{(n-k) !}{(n-k-2 l) !} U_{n-2 l, k} .
$$

Since [9]

$$
\begin{aligned}
& \left(\frac{\partial}{\partial \xi}+i \frac{\partial}{\partial \eta}\right)^{\mu}\left(f\left(\zeta, \sigma^{2}\right)\right)=(\xi+i \eta)^{\mu} 2^{\mu} \frac{\partial^{\mu} f\left(\zeta, \sigma^{2}\right)}{\partial\left(\sigma^{2}\right)^{\mu}} \\
& \left(\frac{\partial}{\partial \xi}-i \frac{\partial}{\partial \eta}\right)^{\chi}\left(f\left(\zeta, \sigma^{2}\right)\right)=(\xi-i \eta)^{\chi} 2^{\chi} \frac{\partial^{\chi} f\left(\zeta, \sigma^{2}\right)}{\partial\left(\sigma^{2}\right)^{\chi}}
\end{aligned}
$$

Applying the previous properties to (4), we determine the result of the operator $\mathrm{P}$

$$
\mathrm{P}^{\mu}\left(U_{n, k}\right)=\frac{(n-k) !}{2^{k}} \sum_{m=0}^{\left[\frac{n-k}{2}\right]} \frac{(-1)^{m} \zeta^{n-k-2 m} \sigma^{2(m-\mu)} 2^{\mu}}{2^{2 m}(m+k) !(n-k-2 m) !(m-\mu) !}(\xi+i \eta)^{k+\mu} .
$$

Substituting $m^{\prime}=m-\mu$, we obtain

$$
\mathrm{P}^{\mu}\left(U_{n, k}\right)=\frac{(n-k) !}{2^{k+\mu}} \sum_{m^{\prime}=0}^{\left[\frac{n-k-2 \mu}{2}\right]} \frac{(-1)^{\mu}(-1)^{m^{\prime}} \zeta^{n-k-2 m^{\prime}-2 \mu} \sigma^{2 m^{\prime}}}{2^{2 m^{\prime}} m^{\prime} !\left(m^{\prime}+k+\mu\right) !\left(n-k-2 m^{\prime}-2 \mu\right) !}(\xi+i \eta)^{k+\mu}
$$

or

$$
\mathrm{P}^{\mu}\left(U_{n, k}\right)=\frac{(-1)^{\mu}(n-k) !}{(n-k-2 \mu) !} U_{n-\mu, k+\mu}
$$

Mathematical Modeling and Computing, Vol. 6, No. 2, pp. 251-257 (2019) 
When differentiating, we take into account that the factor $(\xi+i \eta)^{k}$ is constant with respect to the operator P. It also follows that $\mathrm{P}^{\mu}\left(U_{n, k}\right)=0$ if $\mu>\left[\frac{n-k}{2}\right]$. Therefore, we can write

$$
\mathrm{P}^{\mu}\left(U_{n, k}\right)=\left\{\begin{array}{cl}
\frac{(-1)^{\mu}(n-k) !}{(n-k-2 \mu) !} U_{n-\mu, k+\mu}, & \mu \leqslant\left[\frac{n-k}{2}\right] \\
0, & \mu>\left[\frac{n-k}{2}\right] .
\end{array}\right.
$$

Such approach application for determining the operator $\mathrm{M}$ is impossible, since the multiplier will not be constant with respect to this operator. Thus, we represent a function $U_{n, k}$ using the operator $\mathrm{P}$

$$
U_{n, k}=-\frac{(n-k) !}{(n-k+2) !} \mathrm{P}\left(U_{n+1, k-1}\right), \quad k>0 .
$$

Consequently,

$$
\begin{aligned}
\mathrm{M}\left(U_{n, k}\right) & =-\frac{(n-k) !}{(n-k+2) !} \operatorname{MP}\left(U_{n+1, k-1}\right) \\
& =-\frac{(n-k) !}{(n-k+2) !} \frac{\partial^{2}}{\partial \zeta^{2}}\left(U_{n+1, k-1}\right)=U_{n-1, k-1} .
\end{aligned}
$$

where from

$$
\mathrm{M}\left(U_{n, k}\right)=U_{n-1, k-1}, \quad k>0 .
$$

Applying (10) again, we obtain

$$
\mathrm{M}^{\chi}\left(U_{n, k}\right)=U_{n-\chi, k-\chi}=\ldots=U_{n-k, 0} .
$$

For $\chi>k$, we can make the following transformations, taking into account (11)

$$
\mathrm{M}^{\chi}\left(U_{n, k}\right)=\mathrm{M}^{\chi-k}\left(\mathrm{M}^{k}\left(U_{n, k}\right)\right)=\mathrm{M}^{\chi-k}\left(U_{n-k, 0}\right) .
$$

Now, we apply the equation (9) to the relationship (12), therefore

$$
\mathrm{M}^{\chi-k}\left(U_{n-k, 0}\right)=(n-k) ! \sum_{m=0}^{\left[\frac{n-k}{2}\right]} \frac{(-1)^{m} \zeta^{n-k-2 m} \sigma^{2(m-\chi+k)} 2^{\chi-k}}{2^{2 m} m !(n-k-2 m) !(m-\chi+k) !}(\xi-i \eta)^{\chi-k} .
$$

Substituting $m^{\prime}=m-\chi+k$, we obtain

$$
\mathrm{M}^{\chi-k}\left(U_{n-k, 0}\right)=\frac{(n-k) !(-1)^{\chi-k}}{2^{\chi-k}} \sum_{m^{\prime}=0}^{\left[\frac{n+k-2 \chi}{2}\right.} \frac{(-1)^{m^{\prime}} \zeta^{n+k-2 m^{\prime}-2 \chi} \sigma^{2 m^{\prime}}}{2^{2 m^{\prime}} m^{\prime} !\left(m^{\prime}+\chi-k\right) !\left(n+k-2 m^{\prime}+2 \chi\right) !}(\xi-i \eta)^{\chi-k}
$$

The right side in (13) can be interpreted as the expression $U_{n-\chi, \chi-k}^{*}$ conjugates to the function $U_{n-\chi, \chi-k}$, hence

$$
\mathrm{M}^{\chi}\left(U_{n, k}\right)= \begin{cases}\frac{(-1)^{\chi-k}(n-k) !}{(n+k-2 \chi) !} U_{n-\chi, \chi-k}^{*}, & \beta \leqslant \chi \leqslant\left[\frac{n+k}{2}\right] \\ 0, & \chi>\left[\frac{n+k}{2}\right]\end{cases}
$$

where $(\xi+i \eta)^{\chi-k}=\left((\xi-i \eta)^{\chi-k}\right)^{*}$.

Obviously, the functions $U_{n, k}^{*}$ are also harmonic, and the following identities hold

$$
\operatorname{Re}\left(U_{n, k}^{*}\right)=\operatorname{Re}\left(U_{n, k}\right) \quad \text { and } \quad \operatorname{Im}\left(U_{n, k}^{*}\right)=-\operatorname{Im}\left(U_{n, k}\right) .
$$

Mathematical Modeling and Computing, Vol.6, No. 2, pp. 251-257 (2019) 
Let us proceed to obtain the final formulae. Substituting (8) to the right side of (7), we obtain

$$
\begin{aligned}
\frac{\partial^{\nu}\left(U_{n-\gamma, k}\right)}{\partial \xi^{\alpha} \partial \eta^{\beta}}=\frac{(-i)^{\beta} \alpha ! \beta !}{2^{\nu}} \sum_{l=0}^{\left[\frac{\nu}{2}\right]-\lambda}(-1)^{l} & \frac{(n-k) !}{(n-k-2 l-\gamma) !}\left(D_{\alpha, \beta}^{l} \mathrm{P}^{\nu-2 l}+D_{\alpha, \beta}^{\nu-l} \mathrm{M}^{\nu-2 l}\right) U_{n-2 l-\gamma, k} \\
& +\lambda(\mathrm{PM})^{\left[\frac{\nu}{2}\right]}\left(U_{n, k}\right)=\mathrm{W}_{\alpha, \beta}^{n-\gamma, k}+\mathrm{WW}_{\alpha, \beta}^{n-\gamma, k}+\lambda \mathrm{WWW}_{\alpha, \beta}
\end{aligned}
$$

the operators $\mathrm{W}_{\alpha, \beta}^{n-\gamma, k}, \mathrm{WW}_{\alpha, \beta}^{n-\gamma, k}$ and $\mathrm{WWW}_{\alpha, \beta}$ are as follows

$$
\begin{aligned}
& \mathrm{W}_{\alpha, \beta}^{n-\gamma, k}= \frac{(-i)^{\beta} \alpha ! \beta !}{2^{\nu}} \sum_{l=0}^{\left[\frac{\nu}{2}\right]-\lambda}(-1)^{l} \frac{(n-k) !}{(n-k-2 l-\gamma) !} D_{\alpha, \beta}^{l} \mathrm{P}^{\nu-2 l} U_{n-2 l-\gamma, k} \\
&=\frac{(-i)^{\beta}(-1)^{\nu} \alpha ! \beta !}{2^{\nu}} \sum_{l=\left[\frac{k-n+t+\nu}{2}\right]}^{\left[\frac{\nu}{2}\right]-\lambda}(-1)^{\nu-l} \frac{(n-k) !}{(n-k-t-\nu+2 l) !} D_{\alpha, \beta}^{l} U_{n-t, k+\nu-2 l}, \\
& \mathrm{WW}_{\alpha, \beta}^{n-\gamma, k}= \begin{cases}\sum_{l=0}^{\left[\frac{\nu}{2}\right]-\lambda} \frac{(-1)^{l}(n-k) !}{(n-k-2 l-\gamma) !} D_{\alpha, \beta}^{\nu-l} U_{n-t, k-2 l}, & \nu<k ; \\
\sum_{l=0}^{\left[\frac{\nu-k}{2}\right]-\lambda} \frac{(-1)^{\nu-l}(n-k) !}{(n-t+k+2 l-\nu) !} D_{\alpha, \beta}^{\nu-l} U_{n+\nu-2 l-\gamma, \nu-2 l-k}^{*} & \\
+\sum_{l=\left[\frac{\nu-k}{2}\right]+1}^{\left[\frac{\nu}{2}\right]-\lambda} \frac{(-1)^{l}(n-k) !}{(n-k-2 l-\gamma) !} D_{\alpha, \beta}^{\nu-l} U_{n-t, k-\nu+2 l}, & \nu \geqslant k .\end{cases}
\end{aligned}
$$

and

$$
\mathrm{WWW}_{\alpha, \beta}=(\mathrm{PM})^{\left[\frac{\nu}{2}\right]}\left(U_{n, k}\right)=(-1)^{\left[\frac{\nu}{2}\right]} \frac{(n-k) !}{(n-k-\nu) !} U_{n-\nu, k} .
$$

Combining the formulae (7), (14)-(17), we obtain a general expression for the derivatives $\frac{\partial^{t}\left(U_{n, k}\right)}{\partial \xi^{\alpha} \partial \eta^{\beta} \partial \zeta^{\gamma}}$ $(t=\alpha+\beta+\gamma)$, which is not written here because of bulkness. In addition, they are easier to be analyzed in this form. Since the purpose of the work is not to establish the properties of such relations, detailed research is not performed. Therefore, we give only some of the features of the above relationships. First of all, it follows from formula (7) that the result of differentiation of the function $U_{n, k}$ by the variable $\zeta t$ times is the spherical function of the order $n-t$. Derivatives with respect to two other variables already generate a set of spherical functions of the same order, except the case for an expression $U_{n, n}$ where the result is a polynomial $U_{n-t, n-t}$ ( $t$ is an order of derivative).

Based on these observations and analysis of the results, we can draw the following conclusions.

\section{Conclusions}

The derivatives of internal spherical functions can be represented in a Cartesian coordinate system as a sum of spherical functions of lower orders using the sequence of the formulae (7), (14)-(17). At the same time, these derivatives are harmonic polynomials within the sphere.

The obtained formulae can be used for finding the solutions to problems of mathematical physics for spherical bodies in a Cartesian coordinate system. In addition, such expressions provide a mechanism for studying the structure of the expansion coefficients of the planetary gravitational field potential, 
since they provide an opportunity to present them as a linear combination of geometric parameters and the mass distribution function of a physical body.

[1] Abrikosov O. On computation of a derivatives of the Earth's gravitational potential for satellite geodesy and geodynamics. Kinematics and Physics of Celestial Bodies. 2 (2), 51-58 (1986).

[2] DeWitt R., NAVAL WEAPONS LAB DAHLGREN VA. Derivatives of Expressions Describing the Gravitational Field of the Earth. Defense Technical Information Center (1962).

[3] Antonov V., Baranov A. Relation between the expansions of an external potential in spherical functions and spheroidal harmonics. Technical Physics. 47 (3), 361-363 (2002).

[4] Kholshevnikov K., Shaidulin V. Existence of a class of irregular bodies with a higher convergence rate of Laplace series for the gravitational potential. Celestial Mechanics and Dynamical Astronomy. 122 (4), 391-403 (2015).

[5] Meshcheriakov G. Problems of the potential theory and generalized Earth. Moscow, Nauka (1991).

[6] Hofmann-Wellenhof B., Moritz H. Physical Geodesy. Wien, Springer-Verlag (2006).

[7] Cunningham L. On the computation of the spherical harmonic terms needed during the numerical integration of the orbital motion of an artificial satellite. Celestial mechanics. 2 (2), 207-216 (1970).

[8] Fys M., Zazuliak P., Zajats O. Do pytannia vyznachennia kuliovykh funkcii v zagalnoplanetarnii systemi coordynat. Suchasni dosiagnennia geodesychnoi nauki ta vyrobnyctva. 7, 401-408 (2004).

[9] Hobson E. W. The theory of spherical and ellipsoidal harmonics. Cambridge University Press (1931).

\title{
Представлення внутрішніх кульових функцій та їх похідних у планетарній системі координат
}

\author{
Фис М. М., Бридун А. М., Юрків М. І. \\ Начіональний університет "Львівсъка політехніка", \\ вул. С. Бандери, 12, Львів, 79013, Україна
}

\begin{abstract}
Отримано вирази для сферичних функцій та їх похідних у прямокутній системі координат. На противагу запису многочленів у сферичній системі координат, виведені рекурентні співвідношення дають змогу використовувати їх в описі фізичних процесів у декартовій системі координат, а виведені формули для похідних кульових функцій всередині кулі дозволяють застосовувати їх для отримання розв'язків у прямокутній системі координат задач математичної фізики для тіл кульової форми. В прикладних задачах такий підхід має свої переваги. Наприклад, для визначення руху штучних супутників (їх орбіт) необхідно подати зовнішній потенціал притягання та його похідні для систем GPS у прямокутній системі координат. 3 іншого боку, астрометричні дослідження процесів у галактиках та внутрішньої будови Землі пов'язані з вивченням внутрішнього потенціалу, отже, виникає потреба його подання в прямокутній системі координат.
\end{abstract}

Ключові слова: розподіл мас планети, формула Коші, многочлени Лежандра, тривимірна модель густини, коефічієнти розкладу.

2000 MSC: $86 \mathrm{~A} 20,86 \mathrm{~A} 30,86 \mathrm{~A} 99$

УДК: $528.33: 551.24$ 